\title{
Access to Primary Care in US Counties Is Associated with Lower Obesity Rates
}

\author{
Anne H. Gaglioti, MD, Stephen Petterson, PhD, Andrew Bazemore, MD, MPH, \\ and Robert Phillips, $M D$
}

Background: Obesity causes substantial morbidity and mortality in the United States. Evidence shows that primary care physician (PCP) supply correlates positively with improved health, but its association with obesity in the United States as not been adequately characterized. Our purpose was to characterize the association between PCP supply in US counties and adult obesity.

Methods: We performed a multivariate logistic regression analysis to examine the relationship between county-level PCP supply and individual obesity status. We controlled for individual variables, including sex, race, marital status, income, and insurance status, and county-level variables, including rurality and poverty.

Results: Higher county-level PCP supply was associated with lower adult obesity after controlling for common confounders. Individuals living in counties with the most robust PCP supply were about 20\% less likely to be obese $(P \leq .01)$ than those living in counties with the lowest PCP supply.

Conclusions: While the observed association between the supply of PCPs and lower rates of obesity may not be causal, the association warrants further investigation. This may have important implications for restructuring the physician workforce in the context of the current PCP shortage and implementation of the Affordable Care Act and the patient-centered medical home. (J Am Board Fam Med 2016;29: 182-190.)

Keywords: Access to Health Care, Health Services, Geographic Accessibility, Obesity, Primary Health Care, Public Health

The prevalence of obesity and overweight has increased dramatically over the past 50 years. ${ }^{1}$ According to the 2011 to 2012 National Health and Nutrition Examination Survey, 33.5\% of men and

This article was externally peer reviewed.

Submitted 17 November 2015; revised 30 November 2015; accepted 3 December 2015.

From the Department of Family Medicine, National Center for Primary Care, Morehouse School of Medicine, Atlanta, GA (AHG); and the Robert Graham Center, Washington, DC (SP, AB, RP).

Funding: The Robert Graham Center is supported by the American Academy of Family Physicians but has editorial independence. AHG was a Primary Care Health Policy Fellow at the Georgetown University Department of Family Medicine and the Robert Graham Center at the time this article was developed. Her fellowship was funded by the Georgetown University Department of Family Medicine and Unity Health Care, Inc.

Prior presentation: A portion of the results of this study was presented at the North American Primary Care Research Group annual meeting, Vancouver, British Columbia, Canada (2007). Results from the unadjusted logistic regression model using 2006 data were previously published in American Family Physician in March 2009 in a one-page format. ${ }^{36}$

Conflict of interest: none declared.
$36.5 \%$ of women are obese. ${ }^{2}$ Preventable deaths attributed to overweight and obesity increased by $76 \%$ from 1991 to 2000 , accounting for $17 \%$ of preventable deaths in 2000, making obesity the second leading cause of preventable death in the United States, after smoking., ${ }^{3,4}$ A more recent study estimated that obesity is the third leading preventable cause of death in the United States, accounting for 1 in 10 deaths. ${ }^{5}$ In 2008 the United States spent $\$ 147$ billion on obesity-related health care, accounting for $10 \%$ of all health care spending. ${ }^{6}$ Even after adjusting for potential confounders such as comorbid illnesses and socioeconomic status, medical costs remain higher for obese patients. $^{7-9}$

Corresponding author: Anne H. Gaglioti, MD, Department of Family Medicine, National Center for Primary Care, Morehouse School of Medicine, 720 Westview Dr. SW, Atlanta, GA 30310 (E-mail: agaglioti@msm.edu). 
The severity of the obesity epidemic is undeniable. To date, there have been few effective treatments for weight loss once patients become obese. However, patients who received weight-loss advice from their physician were more likely to eat fewer calories and to exercise than those who did not. ${ }^{10}$ Several recent studies support the effectiveness of a primary care-based model for treatment of obesity. ${ }^{11,12}$ While it is effective, physicians do not practice weight-loss counseling with appropriate regularity, content, or frequency. ${ }^{10,13-16}$ Although the content and frequency of weight-loss counseling by physicians is not yet optimal based on the existing evidence, obese people who come in contact with the health care system are more likely to receive weight-loss counseling than those who do not have adequate access to care.

The impact of access to primary care on the health of individuals and communities remains understudied. However, previous studies support the favorable impact primary care physicians have on obesity. An analysis of the 2002 Behavioral Risk factor Surveillance System (BRFSS) by Mainous et $\mathrm{al}^{17}$ found that obese patients with a usual source of care were more likely to be attempting weight loss than those without a usual provider. Primary care physicians (PCPs) are more likely to practice prevention-related counseling than specialists. ${ }^{18}$ Thus patients who have a primary care physician as their usual source of care are more likely to receive counseling regarding weight loss and maintaining a healthy weight, and to attempt weight loss. In landmark studies by Shi et al ${ }^{19}$ and Starfield et al, ${ }^{20}$ US states with more primary care physicians had lower mortality rates and higher birth weights. ${ }^{19,20} \mathrm{~A}$ compelling ecologic study in Great Britain by Morris and Gravelle ${ }^{21}$ noted that a $10 \%$ increase in the supply of general practitioners was associated with a $4 \%$ decrease in body mass index (BMI).

In light of the impact of obesity on public health and the established association between access to primary care and improved health outcomes, including decreased prevalence of obesity in Great Britain, we examined the association between county-level PCP supply and individual obesity in the United States. Our multivariate logistic regression model controlled for both individual and contextual characteristics associated with obesity status. We hypothesized that the positive ecologic effects of a robust PCP supply would be associated with lower obesity prevalence at the county level.

\section{Methods}

\section{Data Sources}

The BRFSS is a yearly telephone survey of noninstitutionalized civilian adults aged $\geq 18$ years administered by the Centers for Disease Control and Prevention and conducted via state health departments. The BRFSS gathers information on access to health care, preventive care, chronic disease, and health risk behaviors. The survey has been conducted annually since 1984 and collects data from all 50 states, the District of Columbia, Guam, the US Virgin Islands, and Puerto Rico. The survey is conducted via computer-assisted telephone interviewing during every calendar month; calls are made on all days of the week in the day and evening. The 2012 BRFSS survey included cell phone calls in addition to landline calls. Our sample was drawn from the 2012 BRFSS data; the total sample size was 392,535 individuals from 2507 separate US counties, representing about $80 \%$ of all counties in the United States. The BRFSS has a complex multistage sample design that uses poststratification, cluster sampling, and oversampling. ${ }^{22}$

Data from the 2012 American Medical Association Physician Masterfile and the 2010 US Census were used to compute ratios of population to PCPs for each of the 2507 counties; we divided these ratios into quintiles, from lowest to highest primary care access, for ease of display. ${ }^{23,24} \mathrm{We}$ defined PCPs as physicians who designated that they provide direct patient care in the specialties of family medicine, general internal medicine, and general practice. Physicians who did not designate themselves in one of these categories were excluded.

Our adjusted multivariate logistic regression model controlled for individual characteristics including age, sex, race, education, ethnicity, income, insurance coverage, smoking status, marital status, and parental status. We also controlled for county-level variables including rurality, percentage of black residents, and percentage living in poverty.

All variables were selected based on previously established associations to minimize the probability of observing a spurious association between the number of PCPs in a county and obesity rates. Hispanic ethnicity and black race are associated with higher rates of obesity, although these disparities are attenuated in subgroups with high educational attainment. ${ }^{25}$ Obesity rates overall increase with age, and women are more likely to be obese 
than men. ${ }^{2}$ Individuals with higher educational attainment and higher income also have lower rates of obesity. ${ }^{26,27}$ Insured people are more likely to have access to primary care. ${ }^{28}$ Married individuals, especially men, tend to be more obese than those who are unmarried, and smokers tend to be less obese than nonsmokers. ${ }^{29,30}$ Prior studies have shown that obese patients with a usual source of care were more likely to be attempting weight loss. ${ }^{17}$

We also controlled for contextual variables obtained from the area resource file, including "percentage black," defined as the proportion of a county population that was black, and "percentage poverty," defined as the proportion of the county population living below the poverty level. ${ }^{31} \mathrm{We}$ accounted for county-wide poverty based on evidence that shows that individuals who move out of a neighborhood with a high level of poverty to a neighborhood with a low level of poverty have a reduced BMI. ${ }^{32}$ We controlled for metropolitan status of the county using the 2003 rural-urban continuum codes developed by the US Department of Agriculture, because rural populations have poorer access to care than urban populations. ${ }^{33}$ These codes are updated every 10 years. The distribution of the individual and contextual variables across quintiles of primary care access is shown in Table 1.

The main outcome of this research is the odds of an individual living in a county being obese, defined as a $\mathrm{BMI} \geq 30 \mathrm{~kg} / \mathrm{m}^{2} .{ }^{34} \mathrm{BMI}$ was calculated from self-reported height and weight via the BRFSS. The use of self-reported height and weight in epidemiologic studies has been validated, although it has known limitations. ${ }^{35}$

The clinical outcome measure can be stated as the number of obese individuals in each quintile in relation to the total number of individuals in each quintile. All analyses were done using the survey commands in Stata 13.1. Stata uses linearizationbased variance estimators that are appropriate for the design variables provided with the BRFSS data. To assess the fit of the model, we conducted an adjusted Wald test. We initially ran an unadjusted model based on 2006 BRFSS data, which revealed a strong association between high primary care access and low obesity rates. ${ }^{36}$ Because of the large sample size, all the initially selected variables were significant in the unadjusted model and were used in the adjusted model. The association between access to primary care and decreased obesity rates was attenuated but persisted when we adjusted for the individual and county-level variables. This was a secondary analysis of de-identified data and thus did not require institutional review board human subject approval.

\section{Results}

Our analysis revealed an association between robust PCP supply and decreased obesity rates in US counties. As shown in the first row of data in Table $1,25.8 \%$ of adults were obese in counties with the most PCPs (quintile 1), which ranges from 339 to 1232 people per PCP, compared with $30.8 \%$ of adults in counties with the fewest PCPs (quintile 5), which have more than 2126 people per PCP.

Figure 1 displays odds ratios (ORs) from the adjusted multivariate logistic regression model predicting the likelihood of an individual in a quintile to have obesity; these ORs represent the results from the adjusted model, which controlled for both individual and contextual characteristics (Table 2). We found that the likelihood of an adult being obese increased from counties with the most access to primary care to the counties with the least access to primary care. The likelihood of an adult being obese was about 20\% greater in counties with the fewest PCPs when compared with counties with the most PCPs.

Some of the distributions of the individual and county-level characteristics across the quintiles were notable and consistent with previous findings (Table 1). For example, the quintile with the poorest access to PCPs also had the lowest educational attainment, the highest prevalence of poverty, and the lowest average income. By contrast, the quintile with the most PCPs had the highest number of insured people. It is well established that communities with poor access to health care are often disadvantaged when it comes to other social determinants of health, such as education and income. ${ }^{27}$ However, while these disparities are observed in the highest and lowest quintiles, they do not have a linear relationship with obesity rates. Insurance status is not a significant variable in our model, with a confidence interval that includes 1 . Our results reaffirm known disparities regarding obesity, noting the adjusted OR of 1.61 for black individuals relative to whites, as well as an adjusted OR of 0.67 for those with a college education relative to high school graduates. Notably, percentage of the pop- 
Table 1. Distribution of Individual and County-Level Variables by Quintile of Primary Care Physician Supply

\begin{tabular}{|c|c|c|c|c|c|c|}
\hline & $\begin{array}{l}\text { Quintile I (Highest } \\
\text { PCP Supply) }\end{array}$ & Quintile II & Quintile III & Quintile IV & $\begin{array}{l}\text { Quintile V (Lowest } \\
\text { PCP Supply) }\end{array}$ & Mean \\
\hline \multicolumn{7}{|l|}{ Individual variables } \\
\hline Obesity prevalence* & 25.8 & 27.1 & 26.8 & 28.2 & 30.8 & 27.7 \\
\hline \multicolumn{7}{|l|}{ Demographic } \\
\hline Mean age (years) & 47.5 & 47.7 & 47.6 & 47.6 & 47.5 & 47.6 \\
\hline Is a parent & 33.9 & 36.2 & 36.8 & 38.6 & 38.6 & 36.8 \\
\hline Is insured & 84.8 & 85.0 & 83.0 & 80.3 & 79.4 & 82.5 \\
\hline \multicolumn{7}{|l|}{ Education } \\
\hline$<$ High school education & 12.1 & 11.5 & 13.3 & 16.1 & 16.9 & 14 \\
\hline High school graduate & 25.5 & 27.2 & 28.1 & 29.4 & 32.4 & 28.5 \\
\hline Some college & 30.1 & 31.0 & 30.9 & 31.0 & 31.2 & 30.8 \\
\hline College/postgraduate & 32.3 & 30.2 & 27.5 & 23.5 & 19.4 & 26.6 \\
\hline \multicolumn{7}{|l|}{ Race/ethnicity } \\
\hline White & 66.4 & 67.0 & 63.5 & 62.4 & 68.7 & 65.6 \\
\hline Black & 13.4 & 14.3 & 12.4 & 10.6 & 9.5 & 12.0 \\
\hline Hispanic & 13.1 & 8.4 & 15.7 & 19.8 & 16.7 & 14.8 \\
\hline Other & 7.1 & 10.2 & 8.4 & 7.1 & 5.1 & 7.6 \\
\hline \multicolumn{7}{|l|}{ Income (\$/year) } \\
\hline$<15,000$ & 5.1 & 4.6 & 5.1 & 5.8 & 6.1 & 5.4 \\
\hline$<20,000$ & 7.4 & 6.8 & 7.3 & 7.3 & 8.1 & 7.4 \\
\hline$<25,000$ & 7.9 & 7.8 & 7.5 & 8.9 & 9.1 & 8.2 \\
\hline$<35,000$ & 9.2 & 9.2 & 9.6 & 9.7 & 10.1 & 9.6 \\
\hline$<50,000$ & 12.2 & 12.5 & 12.4 & 12.4 & 13.0 & 12.5 \\
\hline$<75,000$ & 13.3 & 14.1 & 13.0 & 13.3 & 14.0 & 13.5 \\
\hline$\geq 75,000$ & 27.5 & 28.8 & 27.5 & 24.3 & 21.5 & 25.9 \\
\hline \multicolumn{7}{|l|}{ Smoking history } \\
\hline Current smoker & 18.0 & 18.4 & 17.6 & 18.4 & 20.9 & 18.6 \\
\hline Former smoker & 25.3 & 25.2 & 25.2 & 24.8 & 24.4 & 25.0 \\
\hline Never smoker & 55.1 & 55.0 & 55.9 & 55.5 & 53.4 & 55.0 \\
\hline \multicolumn{7}{|l|}{ County-level variables } \\
\hline \multicolumn{7}{|l|}{ Black category } \\
\hline Low & 11.7 & 8.8 & 6.0 & 7.2 & 16.6 & 10.1 \\
\hline Low/medium & 15.6 & 16.5 & 18.8 & 13.9 & 17.7 & 16.5 \\
\hline Medium & 17.9 & 13.4 & 25.2 & 27.6 & 25.4 & 21.9 \\
\hline Medium/high & 24.8 & 32.1 & 23.9 & 30.9 & 18.7 & 26.1 \\
\hline High & 30.0 & 29.3 & 26.2 & 20.4 & 21.7 & 25.5 \\
\hline In a metropolitan area & 85.6 & 91.3 & 90.0 & 81.2 & 68.9 & 83.4 \\
\hline \multicolumn{7}{|l|}{ Poverty } \\
\hline Low & 17.3 & 27.9 & 22.5 & 20.7 & 20.6 & 21.8 \\
\hline Low/mid & 30.0 & 22.4 & 22.7 & 14.2 & 20.9 & 22.0 \\
\hline Mid/high & 32.6 & 27.1 & 30.2 & 44.5 & 23.5 & 31.6 \\
\hline High & 20.1 & 22.5 & 24.6 & 20.6 & 35.1 & 24.6 \\
\hline
\end{tabular}

Data are percentages unless otherwise indicated $(\mathrm{N}=392,535$ individuals).

*Obesity is defined as a body mass index $\geq 30 \mathrm{~kg} / \mathrm{m}^{2}$.

Data sources: 2012 Behavioral Risk Factor Surveillance System, 2012 AMA Masterfile, 2010 Census estimates, 2003 rural-urban continuum codes, 2012-2013 area resource files.

ulation that is black at the county level is not a significant contextual variable, and the distribution of the black population is not markedly disparate across the quintiles (Table 2).

\section{Discussion}

In this nationally representative sample, individuals living in counties with the most robust PCP supply were $20 \%$ less likely to be obese than those living in 
Figure 1. Obesity odds ratios across quintiles of US counties from the highest to lowest primary care physician (PCP) supply. Obesity odds ratios are based on a model that controls for individual and county characteristics. Obesity is defined as a body mass index $>30 \mathrm{~kg} / \mathrm{m}^{2}$. Population-to-PCP ratios varied in each quintile: I (highest PCP supply), 339-1232 people/PCP; II, 1233-1430 people/PCP; III, 14311657 people/PCP; IV, 1658-2126 people/PCP; V (lowest PCP supply) $>2126$ people/PCP. Data are from the 2012 Behavioral Risk Factor Surveillance System, the 2012 AMA Physician Masterfile, and 2010 Census estimates of county population.

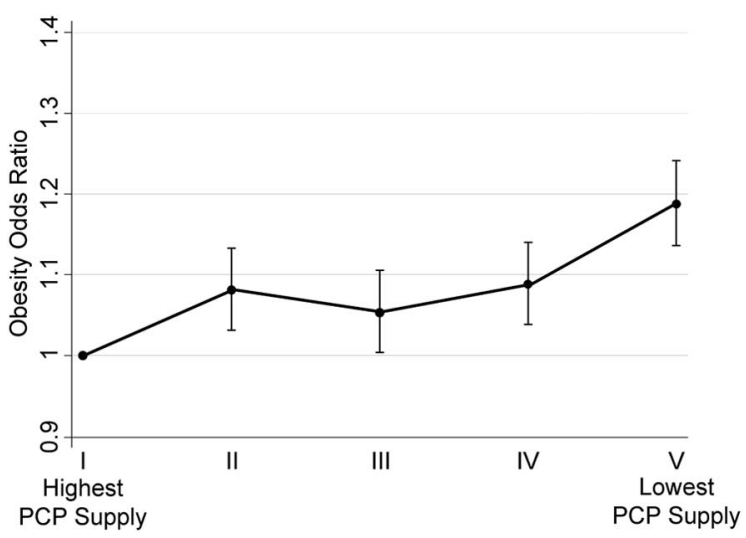

counties with the least supply of PCPs in a model that controlled for both individual and county-level characteristics. The positive ecologic association between county-level PCP supply and obesity presented here is one of many examples of the beneficial ecologic effects of primary care. However, it is important to note that obesity is a complex disease rooted in genetics, individual characteristics, behavior, the socioeconomic milieu, and the environment, ${ }^{37}$ and any solutions to the obesity epidemic will be equally complex. Enhancing primary care access may be one part of a complex solution to the obesity epidemic.

The association reported here does not imply causality, but it has characteristics that point favorably to consideration of a causal relationship. The linear nature of the association between increased PCP supply and decreased obesity rates represents a dose-response effect, which supports an observed association as possible evidence of a causal relationship. ${ }^{38}$ In addition, our results replicate the findings by Morris and Gravelle ${ }^{21}$ that show decreased obesity with increased general practitioner supply in the United Kingdom. Our study builds on these findings, but adds novel aspects. This study was done using the US population on the county level in a health care system that is markedly different from that of Great Britain. It is innovative for a national ecologic study of the benefits of primary care access to be conducted at the county level. Using smaller units of geographic analysis, such as counties, in a national study produces a higher level of local variability within the sample and lends itself to more subtle interpretation of spatial effects. ${ }^{39}$ Previous national studies that have characterized the beneficial effects of the PCP supply have focused on the state level; our study adds to previous studies done at the state level and shows a beneficial relationship between PCP supply at the county level and obesity status.

We wonder what unmeasured characteristics of counties with high levels of primary care access might account for the observation of salutary effects of access to primary care observed in this and other studies. ${ }^{19-21}$ We cannot fully account for the possibility of measuring an endogenous effect. In other words, we cannot account for unmeasured environmental factors that contribute to both decreased obesity rates and the attraction of more PCPs to practice in these counties. For example, physicians may prefer to live and practice in areas that do not have characteristics associated with obesogenic environments, such as low socioeconomic status and limited access to healthy food and public green space. We did account for countylevel income and percentage poverty in our model in an attempt to minimize the measurement of such an effect, but there may be unmeasured variables for which we have not accounted. Notably, the study of general practitioner supply and obesity rates in Great Britain by Morris and Gravelle ${ }^{21}$ accounted for such endogenicity, defined as the probability that the distribution of the PCP supply is dependent on an unobserved factor that also affects BMI; that study found a persistent association with increased general practitioner supply and decreased obesity.

These results also bring into question the explanation that accounts for the mechanism of the observed association between robust PCP supply and decreased obesity. While PCPs are more likely to engage in weight reduction counseling with patients, the effectiveness of these interventions has been shown to be limited. This begs the question, is the effect of primary care supply on population 
Table 2. Obesity Odds Ratios by Individual and Contextual Variables from the Multivariate Regression Model That Adjusted for Individual and County-Level Variables

\begin{tabular}{|c|c|c|}
\hline Variables & $\begin{array}{l}\text { Odds } \\
\text { Ratio }\end{array}$ & $\begin{array}{l}\text { 95\% Confidence } \\
\text { Interval }\end{array}$ \\
\hline \multicolumn{3}{|l|}{$\begin{array}{l}\text { PCP supply in county of } \\
\text { residence }\end{array}$} \\
\hline Quintile 1 (most access) & 1.000 & Index \\
\hline Quintile 2 & $1.081^{*}$ & $1.031-1.133$ \\
\hline Quintile 3 & $1.053^{\dagger}$ & $1.004-1.105$ \\
\hline Quintile 4 & $1.088^{*}$ & $1.039-1.139$ \\
\hline Quintile 5 (least access) & $1.187^{*}$ & $1.136-1.241$ \\
\hline \multicolumn{3}{|l|}{ Individual variables } \\
\hline \multicolumn{3}{|l|}{ Demographic } \\
\hline Age & $1.120^{*}$ & \\
\hline \multicolumn{3}{|l|}{ Education } \\
\hline Some high school & $1.080^{*}$ & $1.023-1.141$ \\
\hline High school graduate & 1.00 & Index \\
\hline Some college & 0.966 & $0.931-1.002$ \\
\hline College graduate & $0.668^{*}$ & $0.642-0.694$ \\
\hline \multicolumn{3}{|l|}{ Parental status } \\
\hline No children & 1.00 & Index \\
\hline Parent & $1.063^{*}$ & $1.023-1.104$ \\
\hline \multicolumn{3}{|l|}{ Race/ethnicity } \\
\hline Non-Hispanic white & 1.00 & Index \\
\hline Black & $1.611^{*}$ & $1.527-1.701$ \\
\hline Hispanic & $1.124^{*}$ & $1.061-1.191$ \\
\hline Other race & $0.681^{*}$ & $0.631-0.735$ \\
\hline \multicolumn{3}{|l|}{ Marital status } \\
\hline Married & 1.00 & Index \\
\hline Never married & 1.048 & $0.999-1.100$ \\
\hline Divorced & 0.993 & $0.956-1.030$ \\
\hline Insured $^{* *}$ & 1.076 & $1.025-1.130$ \\
\hline \multicolumn{3}{|l|}{ Income (\$/year) } \\
\hline$<15,000$ & $1.119^{*}$ & $1.025-1.130$ \\
\hline $15,000-20,000$ & $1.022^{\dagger}$ & $1.025-1.222$ \\
\hline $20,000-25,000$ & 1.002 & $0.924-1.086$ \\
\hline $25,000-35,000$ & $0.890^{*}$ & $0.821-0.966$ \\
\hline $35,000-50,000$ & $0.827^{*}$ & $0.766-0.894$ \\
\hline $50,000-75,000$ & $0.842^{*}$ & $0.766-0.894$ \\
\hline$>75,000$ & $0.659^{*}$ & $0.682-0.713$ \\
\hline \multicolumn{3}{|l|}{ Smoking status } \\
\hline Never smoker & 1.00 & Index \\
\hline Smoker & $0.768^{*}$ & $0.735-0.802$ \\
\hline Former smoker & $1.175^{*}$ & $1.136-1.215$ \\
\hline \multicolumn{3}{|l|}{ County-level variables } \\
\hline Black race $(\%)$ & 1.042 & $0.916-1.185$ \\
\hline \multicolumn{3}{|c|}{ Rural-urban continuum codes } \\
\hline 1 (Most urban) & 1.000 & Index \\
\hline 2 & $1.133^{*}$ & $1.089-1.178$ \\
\hline
\end{tabular}

Table 2. Continued

\begin{tabular}{lcc}
\hline Variables & $\begin{array}{c}\text { Odds } \\
\text { Ratio }\end{array}$ & $\begin{array}{c}95 \% \text { Confidence } \\
\text { Interval }\end{array}$ \\
\hline 3 & $1.171^{*}$ & $1.117-1.227$ \\
4 & $1.222^{*}$ & $1.156-1.292$ \\
5 & $1.179^{*}$ & $1.098-1.265$ \\
6 & $1.187^{*}$ & $1.122-1.256$ \\
7 & $1.190^{*}$ & $1.110-1.274$ \\
8 & 1.081 & $0.950-1.231$ \\
9 (Most rural) & $1.245^{*}$ & $1.070-1.448$ \\
County poverty & & \\
Low & 1.000 & Index \\
Low/mid & 1.038 & $0.994-1.084$ \\
Mid/high & 1.049 & $1.006-1.094$ \\
High & 1.095 & $1.043-1.150$ \\
\hline
\end{tabular}

Data are based on $\mathrm{N}=392,535$ individuals. Obesity is defined as body mass index $\geq 30 \mathrm{~kg} / \mathrm{m}^{2}$.

${ }^{*} P \leq .05$.

${ }^{\dagger} P \leq .01$.

Data Sources: 2012 Behavioral Risk Factor Surveillance System, 2012 AMA Masterfile, 2010 Census estimates of county population, 2003 rural urban continuum codes, and 2012-2013 Area Resource Files.

PCP, primary care physician.

health in small or large areas simply the sum of individual doctor-patient encounters, as a reductionist theoretical framework might suggest, or is it a more complex relationship that goes beyond the individual doctor-patient encounter? Perhaps PCPs also favorably impact the social ${ }^{40}$ and physical environment of the communities where they practice and also improve systems of care. PCPs may improve obesity rates by contributing to the health of their communities in a myriad of ways. PCPs not only improve access to health care and increase patients' exposure to behavior change counseling techniques such as motivational interviewing, as well as other obesity-reducing interventions such as weight-change counseling, medication, or referral for bariatric surgery; they also affect the health of the communities where they practice by advocating for environmental safety, insurance coverage for the uninsured, development of green space, and improved access to healthy food for their communities. In these ways the impact of PCPs occurs not only at the bedside, one patient at a time, but is felt at the health system and community level as well. A study by Gruen et $\mathrm{al}^{41}$ showed that $>90 \%$ of PCPs value community participation and collective advocacy; $>80 \%$ of physicians rated advocacy for obesity and better nutrition as very 
important. Family medicine was the specialty most likely to be civically active. ${ }^{41}$

Our findings are important in light of national trends in PCP supply. A report by the Association of American Medical Colleges projecting future physician supply and demand in the United States estimated a shortage of 65,800 PCPs by the year $2025 .^{42}$ Currently, graduate medical education funding dedicated to ensuring the adequacy of the PCP pipeline has been projected to be inadequate to meet these needs. ${ }^{43,44}$ Our study adds to evidence that supports the development and maintenance of a robust PCP supply that reflects the distribution of the US population.

If further work in this area demonstrates a causal relationship between PCP supply and obesity, our findings would support that improving access to PCPs might improve health disparities related to obesity. This may occur because PCPs engage with the communities where they practice to support strategies for health promotion and disease prevention, promote a healthy ecological environment, and treat individual patients and families with weight-change counseling and other treatments for obesity. Our findings support 2 well-known axioms critically related to health: where we live affects our health, and access to primary care improves health outcomes and reduces cost. ${ }^{19,20,45-47}$

\section{Limitations}

Our study has several limitations. First, while there is an association between improved primary care access and decreased obesity rates, this association does not imply causality. Second, although there is evidence that self-reported height and weight are acceptable measures in the context of ecologic studies, our BMI data would be more accurate if we had access to actual height and weight. It has been shown that height is overreported in general, and men tend to overreport weight whereas women underreport weight. ${ }^{35}$ The likelihood of underestimating BMI increases with age. ${ }^{48-50}$ However, the national data set that reports actual height and weight, the National Health and Nutrition Examination Survey, does not capture enough of the population per US county to perform a meaningful analysis at this level of geography. In addition, we cannot fully account for the fact that these results may be representative of a spurious effect between primary care access and obesity; another study addressed this issue and found that the association persisted when accounting for characteristics that affected physician supply, but these characteristics were not correlated with obesity. ${ }^{21}$

\section{Conclusion}

Our findings of a substantial association between residence in a county with the highest PCP supply and a $20 \%$ decreased risk of individual obesity when compared with individuals residing in counties with the lowest PCP supply adds to evidence supporting the salutary ecologic effects of primary care. In this instance the association relates to a public health epidemic that is a leading cause of preventable early mortality in the United States. In the context of the Affordable Care Act, the projected shortage of PCPs in the United States, and the evolution of the patient-centered medical home that is underway in communities across the country, our findings warrant further studies to discern the mechanisms of action responsible for this ecologic association.

The authors thank Bridget Burke, Barcey Levy, John Ely, George Rust, and Kevin Matthews for their invaluable feedback and editorial comments during the preparation of this article.

\section{References}

1. Parikh NI, Pencina MJ, Wang TJ, et al. Increasing trends in incidence of overweight and obesity over 5 decades. Am J Med 2007;120:242-50.

2. Ogden CL, Carroll MD, Kit BK, Flegal KM. Prevalence of childhood and adult obesity in the United States, 2011-2012. JAMA 2014;311:806-14.

3. Mokdad AH, Marks JS, Stroup DF, Gerberding JL. Actual causes of death in the United States, 2000. JAMA 2004;291:1238-45.

4. Mokdad A, Marks J, Stroup D, Gerberding J. Correction: actual causes of death in the united states, 2000. JAMA 2005;293:293.

5. Danaei G, Ding EL, Mozaffarian D, et al. The preventable causes of death in the United States: comparative risk assessment of dietary, lifestyle, and metabolic risk factors. PLoS Med 2009;6:e1000058.

6. Finkelstein EA, Trogdon JG, Cohen JW, Dietz W. Annual medical spending attributable to obesity: payer-and service-specific estimates. Health Aff (Millwood) 2009;28:w822-31.

7. Bertakis K, Azari R. Obesity and the use of health care services. Obes Res 2005;13:372-9.

8. Fontaine KR, Bartlett SJ. Access and use of medical care among obese persons. Obesity 2000;8:403-6.

9. Centers for Disease Control and Prevention. Division of Nutrition, Physical Activity, and Obesity. Adult obesity causes \& consequences. Economic and 
societal consequences. Last updated June 16, 2015. Available from: http://www.cdc.gov/obesity/adult/ causes.html. Accessed October 29, 2015.

10. Loureiro ML, Nayga RM Jr. Obesity, weight loss, and physician's advice. Soc Sci Med 2006;62:245868.

11. Wadden TA, Volger S, Sarwer DB, et al. A two-year randomized trial of obesity treatment in primary care practice. N Engl J Med 2011;365:1969-79.

12. Appel LJ, Clark JM, Yeh H, et al. Comparative effectiveness of weight-loss interventions in clinical practice. N Engl J Med 2011;365:1959-68.

13. Huang J, Yu H, Marin E, Brock S, Carden D, Davis T. Physicians' weight loss counseling in two public hospital primary care clinics. Acad Med 2004;79: 156-61.

14. McAlpine DD, Wilson AR. Trends in obesity-related counseling in primary care: 1995-2004. Med Care 2007;45:322-9.

15. Stafford RS, Farhat JH, Misra B, Schoenfeld DA. National patterns of physician activities related to obesity management. Arch Fam Med 2000;9:631-8.

16. Bardia A, Holtan SG, Slezak JM, Thompson WG. Diagnosis of obesity by primary care physicians and impact on obesity management. Mayo Clin Proc 2007;82:927-32.

17. Mainous AG, Diaz VA, Koopman RJ, Everett CJ. Having a regular physician and attempted weight loss after screening for hypertension or hypercholesterolemia. Int J Obes 2005;29:223-7.

18. Frank E, Rothenberg R, Lewis C, Belodoff BF. Correlates of physicians' prevention-related practices. Findings from the women physicians' health study. Arch Fam Med 2000;9:359.

19. Shi L, Macinko J, Starfield B, Wulu J, Regan J, Politzer R. The relationship between primary care, income inequality, and mortality in US states, 19801995. J Am Board Fam Pract 2003;16:412-22.

20. Starfield B, Shi L, Macinko J. Contribution of primary care to health systems and health. Milbank Q 2005;83:457-502.

21. Morris S, Gravelle H. GP supply and obesity. J Health Econ 2008;27:1357-67.

22. Centers for Disease Control and Prevention. Behavioral Risk Factor Surveillance System survey data. Atlanta: US Department of Health and Human Services, Centers for Disease Control and Prevention; 2012.

23. American Medical Association. AMA physician masterfile. Chicago: American Medical Association; 2012.

24. US Census Bureau. 2010 Census data. Available from: http://www.census.gov/2010census/data/. Accessed June 18, 2014.

25. Robinson WR, Gordon-Larsen P, Kaufman JS, Suchindran CM, Stevens J. The female-male disparity in obesity prevalence among black American young adults: contributions of sociodemographic characteristics of the childhood family. Am J Clin Nutr 2009;89:1204-12.

26. Sha LL. High school education and obesity: is a GED equal to a high school degree? [master's thesis]. Washington, DC: Georgetown University; 2009.

27. Braveman P. A health disparities perspective on obesity research. Prev Chronic Dis 2009;6:A91.

28. DeVoe JE, Fryer GE, Phillips R, Green L. Receipt of preventive care among adults: Insurance status and usual source of care. Am J Public Health 2003; 93:786-91.

29. Sobal J, Hanson KL, Frongillo EA. Gender, ethnicity, marital status, and body weight in the United States. Obesity 2009;17:2223-31.

30. Umberson D, Liu H, Mirowsky J, Reczek C. Parenthood and trajectories of change in body weight over the life course. Soc Sci Med 2011;73:1323-31.

31. Area Health Resources Files (AHRF). 2012-2013. US Department of Health and Human Services, Health Resources and Services Administration, Bureau of Health Workforce, Rockville, MD.

32. Ludwig J, Sanbonmatsu L, Gennetian L, et al. Neighborhoods, obesity, and diabetes-a randomized social experiment. N Engl J Med 2011;365: 1509-19.

33. Economic Research Service. Measuring rurality: rural-urban continuum codes. Washington, DC: US Department of Agriculture; 2013. Available from: http://www.ers.usda.gov/data-products/rural-urbancontinuum-codes.aspx. Accessed June, 27, 2014.

34. WHO expert committee on physical status: the use and interpretation of anthropometry: report of a WHO expert committee. Geneva: World Health Organization; 1995.

35. Spencer EA, Appleby PN, Davey GK, Key TJ. Validity of self-reported height and weight in 4808 EPIC-oxford participants. Public Health Nutr 2002; 5:561-5.

36. Gaglioti A, Petterson SM, Bazemore AW, Phillips RL Jr, Dodoo MS, Zhang X. Primary care's ecologic impact on obesity. Am Fam Physician 2009;79:446.

37. Mandal B, Chern WS. A multilevel approach to model obesity and overweight in the United States. Columbus: Department of Agricultural, Environmental and Development Economics, Ohio State University; 2007.

38. Hill AB. Principles of medical statistics, 7th ed. New York: Oxford University Press; 1961.

39. Elliott P, Wartenberg D. Spatial epidemiology: current approaches and future challenges. Environ Health Perspect 2004;112:998-1006.

40. Christakis NA, Fowler JH. The spread of obesity in a large social network over 32 years. $\mathrm{N}$ Engl J Med 2007;357:370-9.

41. Gruen RL, Campbell EG, Blumenthal D. Public roles of US physicians. JAMA 2006;296:2467-75. 
42. Dill MJ, Salsberg ES. The complexities of physician supply and demand: projections through 2025. Washington, DC: Association of American Medical Colleges, Center for Workforce Studies; 2008.

43. Petterson SM, Liaw WR, Tran C, Bazemore AW. Estimating the residency expansion required to avoid projected primary care physician shortages by 2035 . Ann Fam Med 2015;13:107-14.

44. Petterson SM, Liaw WR, Phillips RL, Rabin DL, Meyers DS, Bazemore AW. Projecting US primary care physician workforce needs: 2010-25. Ann Fam Med 2012;10:503-9.

45. Starfield B, Shi L. Policy relevant determinants of health: an international perspective. Health Policy 2002;60:201-18.

46. Franks P, Fiscella K. Primary care physicians and specialists as personal physicians. Health care expen- ditures and mortality experience. J Fam Pract 1998; 47:105-9.

47. Fisher ES, Goodman DC, Chandra A; Robert Wood Johnson Foundation. Regional and racial variation in health care among medicare beneficiaries: a brief report of the Dartmouth Atlas Project. Hanover, NH: The Dartmouth Institute for Health Policy \& Clinical Practice, Dartmouth College; 2008.

48. Rowland ML. Self-reported weight and height. Am J Clin Nutr 1990;52:1125-33.

49. Merrill RM, Richardson JS. Validity of self-reported height, weight, and body mass index: findings from the National Health and Nutrition Examination Survey, 2001-2006. Prev Chronic Dis 2009;6:A121.

50. Connor Gorber S, Tremblay M, Moher D, Gorber B. A comparison of direct vs. self-report measures for assessing height, weight and body mass index: a systematic review. Obes Rev 2007;8:307-26. 